\title{
Effect of Buffalo Milk on Rat's Lung Exposed to Noise
}

\author{
Zohre Jafarzadeh (iD ${ }^{1}$, Jamshid Alizadeh ${ }^{1}$ and Massumeh Ahmadizadeh (iD) ${ }^{1,2,{ }^{*}}$ \\ ${ }^{1}$ Department of Occupational Health Engineering, School of Health, Ahvaz Jundishapur University of Medical Sciences, Ahvaz, Iran \\ ${ }^{2}$ Physiology Research Centers, Ahvaz Jundishapur University of Medical Sciences, Ahvaz, Iran \\ "Corresponding author: Physiology Research Centers, Ahvaz Jundishapur University of Medical Sciences, Ahvaz, Iran. Email: ahmadizadeh_m@ajums.ac.ir
}

Received 2019 August 17; Revised 2019 October 08; Accepted 2019 October 12.

\begin{abstract}
Background: Noise is known as annoying sound that can cause damage in auditory and non-auditory systems in humans and animals. The role of diet in reducing the toxicity of xenobiotics has been growing. Milk has found as one of the nutrients with protective effects against the toxic effects of many chemicals.

Objectives: The aim of the present study was to investigate the impact of buffalo's milk(BM) on noise-related injury in rat lung.

Methods: Twenty adult male Wistar rats weighing 200 - $250 \mathrm{~g}$ were provided and kept under standard conditions. The rats were randomly divided into four groups $(n=5)$. Group one was selected as the control group (without administration of buffalo's milk (BM) and no noise exposure). The second group was given BM $(1 \mathrm{~mL} / \mathrm{d})$ and exposed to $100 \mathrm{~dB}$ noise for four hours daily within two consecutive weeks. The animals of third group were exposed to $100 \mathrm{~dB}$ noise for four h daily through two consecutive weeks and the rats of the forth group were treated with BM $(1 \mathrm{~mL} / \mathrm{d})$ daily for two consecutive weeks (without noise exposure). Twenty-four hours after the last treatment, all animals were killed with overdose of sodium pentobarbital. The lung tissues were removed and processed for malondialdeyde (MDA) and glutathione (GSH) biochemical tests and histopathological observations.

Results: Noise exposure increased the level of MDA and reduced GSH level in animals compared to those in the unexposed (control) group. Exposure to noise also caused morphological modification in rat lung. BM did not alter biochemical and histopathological parameters in rat lung compared to the control rats. However, BM significantly decreased MDA and increased GSH levels and caused no obvious damage in the animals exposed to noise.

Conclusions: The results of the present study indicated that noise caused damage in the rat lung and BM protected lung cells against the noise-induced toxicity.
\end{abstract}

Keywords: Buffalo's Milk, Noise, Glutathione, Malondialdehyde, Lung

\section{Background}

Noise pollution, especially for industrial workers has been a global concern. One of the adverse effects of noise has been known as a job stressor that generates various health problems and may cause both auditory and nonauditory harmful effects. Exposure to noise can cause several health disorders in humans and experimental animals, including hypertension, hearing loss and sleep disorder (1). Carugno et al. found that exposure to aircraft noise caused frustration, sleep disorder and hypertension in adults living near the airports (2). Yildirim et al. demonstrated that hearing loss in textile workers is associated with blood oxidative stress (3). Exposure to noise also caused injuries to the liver, kidneys and lung in rat (4). Demirel et al. found noise-induced oxidative stress in rat sera (5). Reduction of antioxidants, including catalase, superoxide dismutase and glutathione (GSH) and also induction of malondialdehyde as an indicator of lipid peroxida- tion were noted in human and experimental animals following exposure to noise $(3,5)$.

Diet plays an important role in reducing the toxic effects of xenobiotics (6). McFadden et al. showed that vitamin $C$ reduced noise-induced hearing loss (7). Puga et al. found the health benefits of nutritional compounds, such as proteins. Vitamins can prevent hearing loss in animal models (8). Milk is one of the main sources of nutrients. It contains many vital elements, including protein, calcium, zinc, vitamin A and vitamin C (9). Water buffalo milk (BM) is consumed in many countries. It contains high levels of vital nutrients and it also exhibits antioxidant properties (9-11). Studies on the role of diet in reducing the toxicity of substances have received much attention from researchers. Recently, it has been reported that milk can have a protective role against chemical-induced toxicity. 


\section{Objectives}

The aim of the present study was to investigate the impact of milk on noise-induced injury in rat lung.

\section{Methods}

Twenty adult male Wistar rats weighting 200 - 250 g were obtained from the maintenance center of laboratory of animals, Ahwaz Jundishapur University Medical Sciences and kept under standard conditions. They were housed in groups of three in clear polypropylene cages in a room with 12-hour light/12-hour darkness cycles and controlled temperature. Animals were allowed to access food and tap water ad libitum. The rats were randomly divided into four groups (each group five animals). Group one was selected as control (without BM administration and no noise exposure). The animals were kept in the chambers with the same specification as that of the experimental groups, except for the noise exposure group. The second group was given $\mathrm{BM}(1 \mathrm{~mL} / \mathrm{d})$ and exposed to $100 \mathrm{~dB}$ noise four hours daily through two consecutive weeks. The animals of the third group were exposed to $100 \mathrm{~dB}$ noise for four hours daily within two consecutive weeks and the rats of the forth group were treated with $1 \mathrm{~mL} / \mathrm{d}$ BM daily for two consecutive weeks (without noise exposure). The methods and amount of milk intake and also the selected sound intensity were based on the previous studies (12-16).

Twenty-four hours after the last treatment, all animals were killed with overdose of sodium pentobarbital. The lung tissues were removed and processed for malondialdeyde (MDA) and GSH biochemical tests as well as histopathological observations.

The method by Buege and Aust was used for evaluation of MDA level (17) and for determination of GSH concentration, Ellman's technique was applied (18).

For histopathological observation, the lung tissues were fixed in formalin and processed for light microscopy using hematoxylin and eosin ( $\mathrm{H} \& \mathrm{E}$ ) staining technique.

\subsection{Data Analysis}

Biochemical data were expressed as mean \pm standard error. Data were analyzed using SPSS 16.0 using one-way analysis of variance (ANOVA), followed by Tukey post hoc test with the probability value of $\mathrm{P}<0.05$ as statistically significant.

\section{Results}

The level of GSH reduced markedly $(\mathrm{P} \leq 0.05)$ in the rats' lungs following exposure to noise compared to the control (unexposed to noise) group. In comparison to the control rats, BM did not alter GSH levels. However, pretreatment with BM and exposure to noise significantly increased GSH levels in comparison to the rats with no pretreatment and exposure to noise (Figure 1).

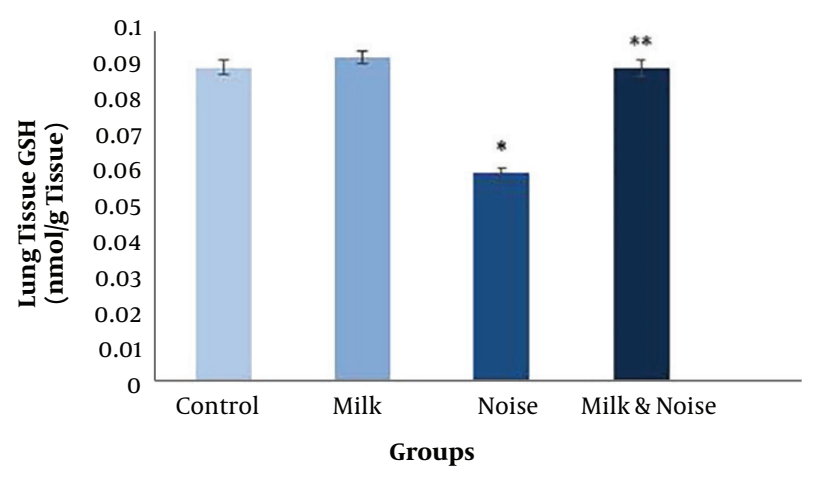

Figure 1. Effect of buffalo milk and noise on rats' lung glutathione (GSH) level. *Sig nificantly different from the control rats $(\mathrm{P} \leq 0.05) ;{ }^{* *}$ significantly different from the noise exposed rats $(\mathrm{P} \leq 0.05)$.

The noise exposure rats showed elevated lung MDA Level than the unexposed group $(\mathrm{P}<0.05)$. BM had no effect on lung MDA level compared to the control group, but significantly diminished MDA level in the exposed rats in comparison to the non-pretreated rats exposed to noise (Figure 2).

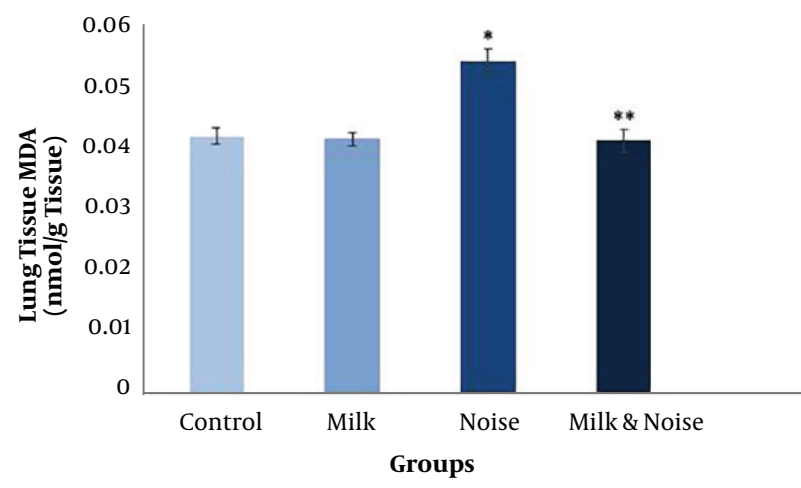

Figure 2. Effect of buffalo milk and noise on rats' lung malondialdehyde (MDA) level. *Significantly different from the control rats $(\mathrm{P} \leq 0.05)$; **significantly different from the noise exposed rats $(\mathrm{P} \leq 0.05)$.

In control rats, lung tissue was intact and there was no detectable injury in the tissues (Figure 3). However, noise caused damage in the lung tissue, which is shown by obvious infiltration of inflammatory cells into alveolar space, thickening of the alveolar cell walls as well as hypertrophy 
of type II epithelial cells (Figure 4). BM had no impact on rats' lung tissues. However, it protected the rats' lung tissues against undesirable effects of noise (Figure 5).

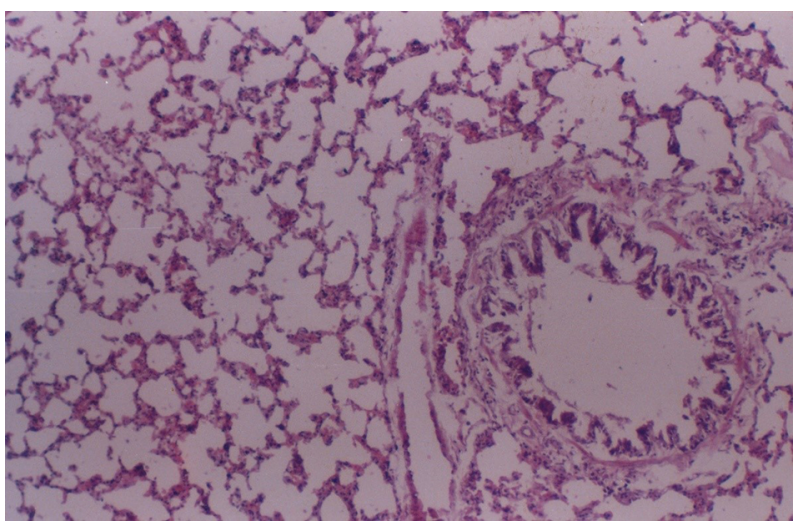

Figure 3. Light micrograph of the lung of the control rat showed no observable in jury to the lung cells $(\mathrm{H} \& \mathrm{E} 20 \times)$.

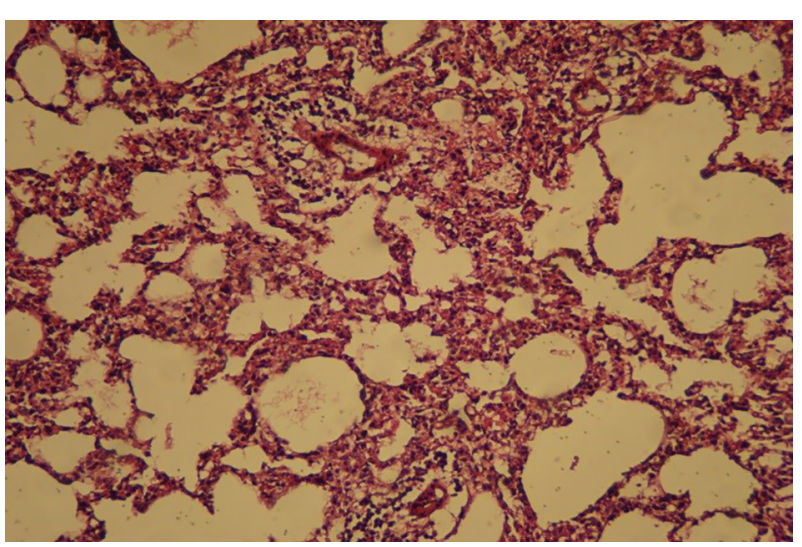

Figure 4. Light micrograph of the lung of the rat exposed to noise, which indicates extensive injuries, including the marked infiltration of inflammatory cells into the alveolar space and septal thickening (H \& E 40×).

\section{Discussion}

Noise pollution is one of the main concerns in modern societies. Noise not only causes hearing loss, but also affects other vital organs, including the liver, kidneys and the respiratory system (4). Several studies have focused on the impact of noise on auditory system. However, the harm effects of noise on the non-auditory organs are increasing. We found that noise induced lung injury in the studied rats. Exposure of noise in rats is associated with the elevation of MDA as an indicator of lipid peroxidation (3)

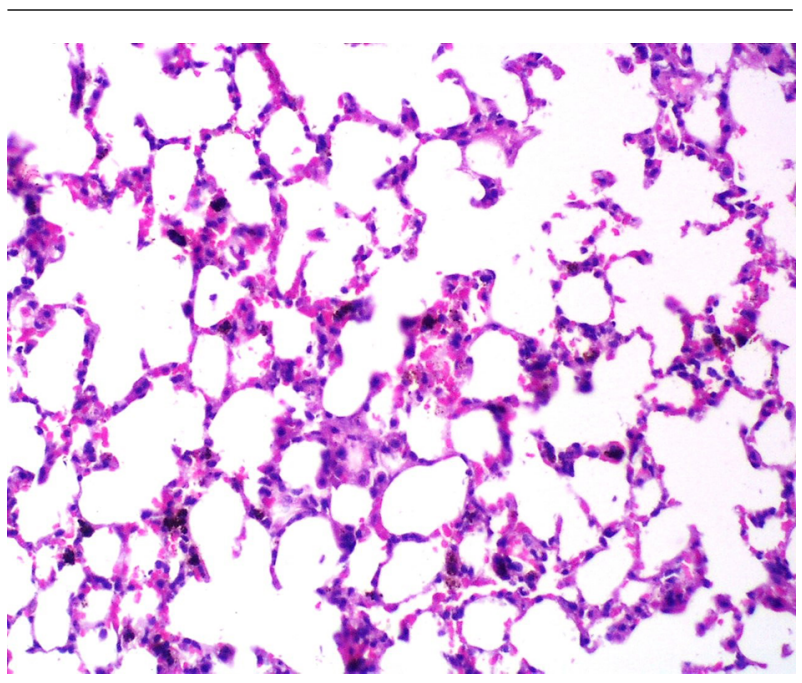

Figure 5. Light micrograph of the lung of rats pretreated with BM and exposed to noise. No obvious injuries were detected in the lung tissue $(\mathrm{H} \& \mathrm{E} 40 \times)$.

and depletion of GSH compared to those in the unexposed control rats. Farzadinia et al. described that noise may have harm effects on male rats' fertility (19). Munzel et al. showed that short-term exposure of aircraft noise induced vascular dysfunction (20). Xue et al. found that high frequency steady noise induced histopathological damages in various rat vital organs, including brain, liver, spleen and heart tissue (21). Oliveira et al. reported that the rats exposed to noise showed the significant enhancement of connective tissue in centrilobular zone of the liver (14). Grande et al. described lung parenchyma alteration in rat lung following exposure to noise (22). Modification of rat tracheal epithelial cells was observed following exposure to noise (23). Structural and functional damages were noted in rat lung after exposure to high-energy impulse noise (24).

Similar to other tissues, lung is also susceptible to the noise-induced toxicity. Noise-induced oxidative stress in lung tissue has generally accepted $(3,5)$. Elsayed et al. reported that exposure to blast waves caused damaged rat lung. They also showed that exposure to blast waves induced reactive free-radical intermediates in the lung characterized by lipid peroxidation and depleted antioxidant level (25). Pretreatments of rats with vitamin E as an antioxidant agent reduced oxidative stress caused by noise exposure in rat lung (26).

It is generally considered that proper diet can potentially protect the living organism against harmful effects of reactive chemical species (27).

Water buffalo milk is consumed in many countries. It contains high levels of vitamin A, iron, copper, phospho- 
rous, magnesium and other trace elements with antioxidant activity, as well (9-12).

To our knowledge, the effect of milk on noise-induced lung injury has not yet been reported.

Our findings showed that treatment with BM prior to noise exposure alleviated noise-induced injury in rat lung. The protective role of BM could be attributed to its antioxidant capacity.

\subsection{Conclusions}

Our results indicated noise-induced injury in rat lung. Our findings indicating that noise elevated MDA and depleted GSH levels support the fact that generation of oxidative stress in the lung at least in part is associated with lung toxicity. BM has an antioxidant property and is able to prevent lung tissue against adverse effects of noise.

\section{Acknowledgments}

The authors are thankful to the Deputy of Research and Physiology Research Center of Ahvaz Jundishapur University of Medical Sciences. We are also grateful to Dr. Malaeke A. for reviewing histopathological samples.

\section{Footnotes}

Authors' Contribution: Zohre Jafarzadeh and Jamshid Alizadeh provided technical assistance and also collection and preparation of the manuscript. Massumeh Ahmadizadeh designed and supervised the study and prepared the final draft of the article.

Conflict of Interests: The authors declared no competing interests.

Ethical Approval: The research followed the tenets of the Declaration of Helsinki. This study was approved by the Ethics Committee of Ahvaz Jundishapur University of Medical Sciences. Prior to the experiment, the research protocol was confirmed to be in accordance with the guidelines of Animal Ethics Committee of Ahvaz Jundishapur University of Medical Sciences (IR.AJUMS.REC.1395.33).

Funding/Support: The current study was supported by the Physiology Research Center and the Research Deputy of Ahvaz Jundishapur University of Medical Sciences (grant No.: APRC-94-12).

\section{References}

1. Basner M, Babisch W, Davis A, Brink M, Clark C, Janssen S, et al. Auditory and non-auditory effects of noise on health. Lancet. 2014;383(9925):1325-32. doi: 10.1016/S0140-6736(13)61613-X. [PubMed: 24183105]. [PubMed Central: PMC3988259].
2. Carugno M, Imbrogno P, Zucchi A, Ciampichini R, Tereanu C, Sampietro G, et al. Effects of aircraft noise on annoyance, sleep disorders, and blood pressure among adult residents near the Orio al Serio International Airport (BGY), Italy. Med Lav. 2018;109(4):253-63. doi: 10.23749/mdl.v109i4.7271. [PubMed: 30168498].

3. Yildirim I, Kilinc M, Okur E, Inanc Tolun F, Kilic MA, Kurutas EB, et al. The effects of noise on hearing and oxidative stress in textile workers. Ind Health. 2007;45(6):743-9. doi: 10.2486/indhealth.45.743. [PubMed: 18212468].

4. Zymantiene J, Zelvyte R, Pampariene I, Aniuliene A, Juodziukyniene $\mathrm{N}$, Kantautaite J, et al. Effects of long-term construction noise on health of adult female Wistar rats. Pol J Vet Sci. 2017;20(1):155-65. doi: 10.1515/pjvs-2017-0020. [PubMed: 28525342].

5. Demirel R, Mollaoglu H, Yesilyurt H, Ucok K, Aycicek A, Akkaya M, et al. Noise induces oxidative stress in rat. Eur J Gen Med. 2009;6(1):20-4. doi: $10.29333 /$ ejgm/82631.

6. Wu JC, Lai CS, Tsai ML, Ho CT, Wang YJ, Pan MH. Chemopreventive effect of natural dietary compounds on xenobiotic-induced toxicity. J Food Drug Anal. 2017;25(1):176-86. doi: 10.1016/j.jfda.2016.10.019. [PubMed: 28911535].

7. McFadden SL, Woo JM, Michalak N, Ding D. Dietary vitamin C supplementation reduces noise-induced hearing loss in guinea pigs. Hear Res. 2005;202(1-2):200-8. doi: 10.1016/j.heares.2004.10.011. [PubMed: 15811712].

8. Puga AM, Pajares MA, Varela-Moreiras G, Partearroyo T. Interplay between nutrition and hearing loss: State of art. Nutrients. 2018;11(1) doi: 10.3390/nu11010035. [PubMed: 30586880]. [PubMed Central: PMC6356655].

9. Ghada Z, Soliman A. Comparison of chemical and mineral content of milk from human, cow, buffalo, camel and goat in Egypt. Egypt J Hosp Med. 2005;21:116-30.

10. Ahmad S, Anjum FM, Huma N, Sameen A, Zahoor T. Composition and physico-chemical characteristics of buffalo milk with particular emphasis on lipids, proteins, minerals, enzymes and vitamins. J Anim Plant Sci. 2013;23:62-74

11. Khan IT, Nadeem M, Imran M, Ullah R, Ajmal M, Jaspal MH. Antioxidant properties of milk and dairy products: A comprehensive review of the current knowledge. Lipids Health Dis. 2019;18(1):41 doi: 10.1186/s12944-019-0969-8. [PubMed: 30717735]. [PubMed Central: PMC6362592].

12. Afravy M, Angali K, Khodadadi A, Ahmadizadeh M. The protective effect of buffalo's milk against toluene induced-nephrotoxicity in rats. J Nephropathol.2017;6(3):174-9. doi:10.15171/jnp.2017.30. [PubMed: 28975098]. [PubMed Central: PMC5607980].

13. Jaffarzadeh Z, Alizadeh J, Ahmadizadeh M. The outcome of noise pollution omn rat lung. Biochem Cell Arch. 2019;19(1):75-8.

14. Oliveira MJ, Freitas D, Carvalho AP, Guimaraes L, Pinto A, Aguas AP. Exposure to industrial wideband noise increases connective tissue in the rat liver. Noise Health. 2012;14(60):227-9. doi: 10.4103/14631741.102959. [PubMed: 23117537].

15. Samson J, Sheeladevi R, Ravindran R, Senthilvelan M. Stress response in rat brain after different durations of noise exposure. $\mathrm{Neu}$ rosci Res. 2007;57(1):143-7. doi:10.1016/j.neures.2006.09.019. [PubMed: 17092591].

16. Manikandan S, Srikumar R, Jeya Parthasarathy N, Sheela Devi R Protective effect of Acorus calamus LINN on free radical scavengers and lipid peroxidation in discrete regions of brain against noise stress exposed rat. Biol Pharm Bull. 2005;28(12):2327-30. doi: 10.1248/bpb.28.2327. [PubMed:16327175].

17. Buege JA, Aust SD. Microsomal lipid peroxidation. Methods Enzymol 1978;52:302-10. doi:10.1016/s0076-6879(78)52032-6. [PubMed: 672633].

18. Ellman GL. Tissue sulfhydryl groups. Arch Biochem Biophys. 1959;82(1):70-7. doi: 10.1016/0003-9861(59)90090-6. [PubMed: 13650640]. 
19. Farzadinia P, Bigdeli M, Akbarzadeh S, Mohammadi M, Daneshi A, Bargahi A. Effect of noise pollution on testicular tissue and hormonal assessment in rat. Andrologia. 2016;48(9):869-73. doi: 10.1111/and.12524. [PubMed: 26762793].

20. Munzel T, Daiber A, Steven S, Tran LP, Ullmann E, Kossmann $S$, et al. Effects of noise on vascular function, oxidative stress, and inflammation: Mechanistic insight from studies in mice. Eur Heart J. 2017;38(37):2838-49. doi: 10.1093/eurheartj/ehx081. [PubMed: 28329261]. [PubMed Central: PMC5837459].

21. Xue L, Zhang D, Xiaokaiti Y, Wang T, Shou X. Effects of high frequency noise on female rat's multi-organ histology. Noise Health. 2014;16(71):213-7. doi: 10.4103/1463-1741.137048. [PubMed: 25033787].

22. Grande NR, Aguas AP, De Sousa Pereira A, Monteiro E, Castelo Branco NA. Morphological changes in rat lung parenchyma exposed to low frequency noise. Aviat Space Environ Med. 1999;70(3 Pt 2):A70-7. [PubMed: 10189159].

23. Oliveira MJ, Pereira AS, Guimaraes L, Freitas D, Carvalho AP, Grande NR, et al. Chronic exposure of rats to cotton-mill-room noise changes the cell composition of the tracheal epithelium. J Occup Environ Med. 2002;44(12):1135-42. doi: 10.1097/00043764-200212000-00007. [PubMed: 12500455].

24. Armstrong KL, Cooper MF, Williams MT, Elsayed NM. Vitamin E and lipoic acid, but not vitamin $C$ improve blood oxygenation after highenergy IMPULSE noise (BLAST) exposure. Biochem Biophys Res Commun. 1998;253(1):114-8. doi: 10.1006/bbrc.1998.9762. [PubMed: 9875229].

25. Elsayed NM, Gorbunov NV. Pulmonary biochemical and histological alterations after repeated low-level blast overpressure exposures. Toxicol Sci. 2007;95(1):289-96. doi: 10.1093/toxsci/kfl138. [PubMed: 17060374].

26. Elsayed NM, Armstrong KL, William MT, Cooper MF. Antioxidant loading reduces oxidative stress induced by high-energy impulse noise (blast) exposure. Toxicology. 2000;155(1-3):91-9. doi: 10.1016/s0300483x(00)00281-x. [PubMed: 11154801].

27. Furst A. Can nutrition affect chemical toxicity? Int $J$ Toxicol. 2002;21(5):419-24. doi: 10.1080/10915810290096649. [PubMed: 12396688]. 